\title{
2013/24
}

Reforming the postal universal service

Axel Gautier and Jean-Christophe Poudou

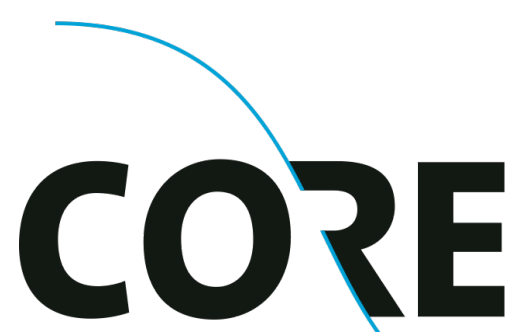

DISCUSSION PAPER

Center for Operations Research and Econometrics

Voie du Roman Pays, 34 B-1348 Louvain-la-Neuve Belgium http://www.uclouvain.be/core 


\title{
CORE DISCUSSION PAPER \\ $2013 / 24$
}

\section{Reforming the postal universal service}

\section{Axel GAUTIER ${ }^{1}$ and Jean-Christophe POUDOU ${ }^{2}$}

April 2013

\begin{abstract}
The postal sector has undergone dramatic changes over the recent years under the double effect of ongoing liberalization and increased competition with alternative communication channels (esubstitution). As a result, the mail volume handled by the historical operator has declined sharply while the latter's ability to match the same standard of universal service may be under threat. Thus, a reform of the postal universal service is on the agenda. This paper examines possible reforming options ranging from keeping universal service within the postal sector to redefining universal service as spanning postal and electronic technologies.
\end{abstract}

Keywords: universal service, postal market, digitalization

JEL Classification: L51, L86, L87

\footnotetext{
${ }^{1}$ University of Liège (ULg), HEC Management School, B-4000 Liège, Belgium; Université catholique de Louvain, CORE, B-1348 Louvain-la-Neuve, Belgium. E-mail: agautier@ulg.ac.be

${ }^{2}$ LAMETA, University of Montpellier and LabEx "Entreprendre", Montpellier, France. E-mail: jpoudou@univ-montp1.fr

The authors are grateful to Lionel Janin and Xavier Wauthy and to the participants at the $7^{\text {th }}$ Postal conference on the economics of the postal sector in a digital world (Toulouse, March 2012) for their helpful comments and suggestions.
} 


\section{Introduction}

Whereas the postal sector has a long tradition of providing universal service its future is now under debate. The recent market liberalization (in Europe) and the growing use of electronic media have both contributed to eroding the mail flow handled by the universal service provider. In most developed economies, volumes are declining. In France, for instance, mail volume has declined around 3.5\% per year on average since 2007. A trend which is clearly related to the digitalization of the economy and e-substitution. Consumers have alternatives to paper communications: e-mail and phone calls instead of personal letters, SMS instead of Season's greetings, on-line bill and commercial documents, on-line newspapers, e-administration, e.g. for tax statement and payment, on-line advertising etc. In the long run, declining volumes may threaten the sustainability of the universal postal service (Crew and Kleindorfer, 2005) and the digitalization of the economy makes a reform of the latter more necessary.

In the postal sector, the universal service is defined along three dimensions (Ambrosini et al., 2006): The range of products, the quality of service and the pricing constraints (affordability, uniform pricing). The quality of postal services has multiple aspects including territorial coverage (ubiquity), transit time, accessibility of contact points and delivery frequency. One particularity of the universal postal service is that it is truly ubiquitous. With few exceptions, everyone has a postal address and hence is a user of the postal service, eventually only has a receiver. ${ }^{1}$

Nowadays, the main competitor of the postal sector is the internet. Despite a rapid growth, internet is far from being ubiquitous. In the EU-27, the internet penetration rate $^{2}$ was $73 \%$ in 2011 (Source: Eurostat) with most of the households using a broadband connection. ${ }^{3}$ Reasons for not being connected are numerous: lack of interest, lack of competence (digital illiteracy), service cost, equipment cost and non-availability of the service in the area (mainly for broadband connections). Indeed, broadband connections are not available everywhere. While metropolitan areas are usually

\footnotetext{
${ }^{1}$ This is in contrast with the universal service in telecommunications where there is a difference between the availability and the use of the service. For instance, the Universal Service European Directive (2002/22/EC) imposes that a fixed connection to the public phone network be made available to all users on request, independently of geographical location. At the same time, consumers are cutting the cord and recent evidence from the US suggests that, despite a growing offer of services, the universal service is currently declining (Gideon and Gabel, 2011).

${ }^{2}$ The percentage of households with an internet connection.

${ }^{3}$ The broadband penetration rate was $68 \%$ in 2011 (source: Eurostat).
} 
well-connected, this is not necessarily the case of rural and less-populated regions where the deployment of infrastructure is more costly. ${ }^{4}$ Table 1 illustrates the lack of infrastructure in less-populated areas for the EU-27. This shows survey data collected by Eurostat on the reasons for not having a broadband connection at home. Interestingly, household in less populated areas mention more frequently the lack of infrastructure than those living in more populated places. ${ }^{5}$

\begin{tabular}{|lcc|}
\hline Population density & 2007 & 2009 \\
\hline.$>500 \mathrm{hab} / \mathrm{km}^{2}$ & 10 & 9 \\
$100<.<499 \mathrm{hab} / \mathrm{km}^{2}$ & 20 & 22 \\
.$<100 \mathrm{hab} / \mathrm{km}^{2}$ & 34 & 30 \\
\hline Source: Eurostat & &
\end{tabular}

Table 1: Households without broadband connection because it is not available in the area expressed as a percentage of households without broadband access

The postal sector is thus competing with a new technology that is not (yet?) deployed everywhere. ${ }^{6}$ Our first research question is to investigate the impact of electronic communications on the design of the universal postal service. Given competition from the internet, how should the universal service be reformed? To our knowledge, this question has not yet been treated explicitly even though several authors have focused on the related question of reforming the universal service obligations (hereafter USO) after entry of a postal competitor. ${ }^{7}, 8$ Crew and Kleindorfer (2007) focusing on the accessibility of contact points argue that the USO should be reduced after entry. The argument is based on economies of scale and scope that can no longer be exploited in a competitive environment. Gautier and Paolini (2011) and Gautier and Wauthy (2012) argue that lightening the universal service is a tool to keep the universal service sustainable in a competitive

\footnotetext{
${ }^{4}$ This situation is likely to last with the deployment of 'next generation access networks' (NGANs) that are currently concentrated in business districts and city centers.

${ }^{5}$ The existence of a digital divide between urban and rural regions is now welldocumented (Billón et al., 2009; Bouckaert et al., 2010) and can partially be accounted for a lack of infrastructure.

${ }^{6}$ Some countries (notably Swiss and Finland) have included broadband connection as part of the universal service.

${ }^{7}$ The privatization of postal operators has also leaded to a decline in the quality of the universal service as documented by Schuster (2013).

${ }^{8}$ Reforming the telecom USO is also on the agenda, see Alleman et al. (2010).
} 
environment. On the contrary, Calzada (2009) shows that the entry of a low-quality postal competitor with a limited territorial coverage and lower delivery frequency increases the quality offered by the incumbent.

In this paper, we consider a model of competition between two communication technologies, the internet and the postal service, each one being identified by a unique provider. Internet and postal services differ on two dimensions: territorial coverage and service quality. As mentioned, broadband connections are currently not available everywhere due to a lack of infrastructure. In the sequel, we distinguish two areas within the country: a urban region where broadband internet is made available to end-users and a rural region where it is not. By contrast, postal services are ubiquitous, often because the ubiquity constraint is part of the universal service definition. Quality of communication has several dimensions (security, reliability, speed of delivery etc). In this paper, we focus exclusively on one dimension, delivery frequency ${ }^{9}$, on which the internet has a clear advantage. Our model differs from Calzada (2009) as we consider that each technology dominates the other in one dimension: while the internet allows faster delivery it is not available everywhere. In this context, we consider the following question: should the postal USO be reformed as the households use increasingly the internet rather than the postal services for their communication? And the reform we consider is a change in delivery frequency. Currently, the universal service imposes five or six day a week delivery and possibly sometimes an additional early delivery for newspapers. ${ }^{10}$ When technologies are competing, the internet skims the most profitable customers of the urban market which results in (1) lower profits for the postal firm because of e-substitution and (2) the remaining clients in the urban area being those with a low willingness to pay for quality. For these reasons, welfare-maximization calls for a universal postal service of lower quality. Reducing delivery frequency is motivated primarily by a lower (average) willingness to pay for quality as those who are the more interested in high-speed communication in the urban area no longer use postal services. In addition, as competition erodes mail volume and quality is costly to deliver, financial constraints may call for a further reduction of delivery frequency. The digitalization of the communications calls for a lightening of the postal USO and, there are, indeed, projects to reform the USO in such a way. ${ }^{11}$

\footnotetext{
${ }^{9}$ Or equivalently on the transit time.

${ }^{10}$ Delivery of newspapers is sometimes included as an additional requirement of the universal service, see Ambrosini et al., (2006).

${ }^{11}$ In The Netherlands where the overall letter volume has dropped by $14 \%$ over the period 2005-10, the government plans to reform the USO and considers dropping the
} 
But, such a reform of the USO would create a regional divide between rural and urban areas. In the latter, the two technologies compete, resulting in lower prices and consumers can choose their preferred communication means. In the rural area, consumers are offered a lower service quality without having the option to switch to the new technology. To overcome this regional divide, the universal service can be broadened to include both the electronic and the postal technology to provide a reformed communication universal service. ${ }^{12}$ Our second research question consists in a comparative analysis of different possible definitions of a reformed communication USO. In particular, we consider the following alternatives. First, the implementation of a universal service fund to share the financial burden of the USO between the two firms. The universal service is still provided by the postal operator but the cost is shared between the two technologies. Second, a broader USO where the postal universal service is completed by the imposition of a ubiquity constraint on the internet to make broadband available everywhere. And third, a change of technology for the universal service. Accordingly, the postal operator is relieved from any USO and the regulator imposes a universal service for the internet. All these options aim at increasing the quality of services, especially in the rural area, either by increasing the quality of the postal service or by increasing the broadband penetration. Our objective is to compare the quality of services, the broadband penetration, the need for public funding and ultimately the welfare resulting from these alternatives. Finally, we consider a technological mix where the postal network is used to distribute electronic media. Currently, there are a lot of initiatives to launch hybrid mail services, e.g. for registered mail. Hybrid mail uses both the internet and the physical postal network for mail delivery. Hybrid mail is prepared and sent electronically on computers but distributed physically in mailboxes. ${ }^{13}$ The development of hybrid mail might be an interesting alternative in order to provide high quality services in the rural area when nationwide coverage by the internet is too costly to implement.

This paper is organized as follows. Section 2 introduces our model and our main assumptions. Section 3 considers the postal universal service and Section 4 a broader communication USO. Section 5 compares the different reform options. Finally, Section 6 presents our conclusions. All the proofs

Monday delivery and thus reducing delivery frequency to 5 days. Similar reforms are under discussion in Norway where the Saturday delivery could be abandoned.

${ }^{12}$ On this point, see Jaag and Trinkner (2011).

${ }^{13}$ Reverse hybrid mail is prepared physically but stored and distributed electronically. Reverse hybrid mail is not considered in this paper. 
are relegated in the Appendix.

\section{Model}

Consumers We consider a country composed of a continuum of size one of local markets or cities. A local market is either part of the urban region $(u)$ or the rural region $(r)$. The urban region is composed of $n^{u}$ cities and the rural one of $n^{r}=1-n^{u}$ cities and we set $n^{u}=n>0$. In each city, there is a mass one of customers. Each customer is characterized by a taste for quality parameter $\theta$. We assume that $\theta$ is uniformly distributed on $[\underline{\theta}, \bar{\theta}]$ and $\Delta \theta=\bar{\theta}-\underline{\theta}=1$. Furthermore, we assume that $\bar{\theta} \geq 2 \underline{\theta}$ so that $\underline{\theta} \in] 0,1]$. The utility of customer of type $\theta$ when he consumes a good of quality $x$ at price $p$ is equal to $U(\theta)=\theta x-p$. Consumers buy one unit of the good when $U(\theta) \geq 0$.

Firms There are two firms: firm 1 is the postal operator, firm 2 is the internet provider. Firms provide differentiated services to customers and compete in price for consumers in each city. ${ }^{14}$ We identify the quality of the service by a unique dimension $x$, the speed of delivery. The internet offers the highest possible quality $x_{2}$ as delivery of messages is instantaneous. The postal operator offers services of quality $x_{1}<x_{2}$; the quality $x_{1}$ is flexible and it can be understood as delivery frequency. Despite its flexibility, the quality offered by the postal firm can vary only within a certain range and we define a lower bound on the quality of postal services. We will assume that $x_{1}$ must belong to the interval $\left[\bar{x}_{1}, x_{2}\right]$; the lower boundary will be formally defined hereafter to guarantee that, at equilibrium prices, the market is fully covered.

To operate in region $u, r$, firm 2 must deploy its broadband telecommunication network. Infrastructure costs are given by $F^{u}$ for the urban region and $F^{r}>F^{u}$ for the rural one. We will assume that $F^{r}$ is sufficiently large so that it is not profitable for the internet to connect the rural region (see the formal condition in Equation 5) and, without loss of generality, we set $F^{u}=0$ and $F^{r}=F>0$. Once a region is connected, there is no other cost of providing the service.

Delivering mail at frequency $x_{1} \operatorname{costs} k^{u} x_{1}^{2} / 2$ in the urban region and $k^{r} x_{1}^{2} / 2$ in the rural one and we assume that $k^{r}>k^{u}$ i.e. mail delivery is

\footnotetext{
${ }^{14}$ Obviously price competition is a shortcut way to encompass a broader variety of competitive environement in which firms can be put in. This allows us to discuss about market competition of both technologies using a simple standard model of vertical differentiation.
} 
more costly in the rural area due to a lower population density. We further assume that the cost of quality $x_{1}$ per user is higher in the rural area meaning $k^{r} /(1-n)>k^{u} / n$. Our modeling assumption captures the fact that delivery costs are mainly driven by delivery frequency and not by the mail volume. ${ }^{15}$ In the sequel, we use the notation $k=k^{r}+k^{u}$. In addition, the provision of postal services requires a fixed cost $f$. This cost encompasses all the dimensions of postal services that are not linked to delivery such as post offices. As for the internet, the marginal cost of the postal services is set to zero (for simplicity).

Universal service obligations We consider that the universal service consists in making available to all users a service of given quality at an affordable rate. ${ }^{16}$ More specifically, we will consider that the universal service obligations are made of the following requirements:

- Ubiquity: the service must be offered in all local markets.

- Affordability: the service must be affordable to all consumers, that is the quality-price combination of the universal service provider must satisfy $U(\underline{\theta}) \geq 0 .{ }^{17}$

- Uniform quality: the quality of the universal service must be identical for all users irrespective of their geographical location.

Note that we do not include any other constraint on the prices than the affordability constraint. Thus, we allow the universal service provider to price discriminate between regions as long as the prices satisfy the affordability constraint. The affordability constraint is thus an upper price limit.

Timing of the events We consider the following sequence of decisions:

- The regulator defines the universal service obligations. It specifies which universal service constraint applies and to whom. The USO

\footnotetext{
${ }^{15}$ In the postal sector, the cost elasticity is usually rather small. Boldron et. al (2007) estimate a cost elasticity of 0.25 for Germany and 0.31 for France. Conversely, the cost is quite sensitive to delivery frequency. In the same paper, Boldron et. al (2007) report the savings associated with a reduction of delivery frequency. They estimate that the French postal operator would reduce its cost by $29 \%$ if delivery frequency was reduced to 3 days a week and savings are especially high in low density areas.

${ }^{16}$ For the economic motivations for the universal service, see Cremer et al. (2006).

${ }^{17}$ This specification of the affordability constraint is similar to Calzada (2009).
} 
must be designed taking into account that a firm must realize a nonnegative profit. Otherwise, participation is not guaranteed.

- If not specified in the USO, firms decide on market coverage and on the quality of the postal service.

- Firms compete on prices, subject to the price constraints specified in the USO.

\section{Postal USO}

\subsection{Benchmark: designing a postal USO in a non-competitive environment}

Suppose that the postal technology is the only one available. Under the assumption of a fully covered market, the profit realized by firm 1 is:

$$
\pi_{1}^{m}\left(x_{1}\right)=p_{1}-k x_{1}^{2} / 2-f
$$

Subject to the constraints of affordability and uniform quality, the profitmaximizing price and quality are given by:

$$
x_{1}^{m}=\frac{\theta}{k} \text { and } p_{1}^{m}=\underline{\theta} x_{1}^{m}
$$

In the sequel, we will assume that $\pi_{1}^{m}\left(x_{1}^{m}\right) \geq 0$, meaning that quality $x_{1}^{m}$ can be delivered to all profitably (so that $f<f_{0}=\frac{1}{2} \underline{\theta}^{2} / k$ ).

Define the welfare as the sum of the consumers' utility and the firm's profit:

$$
W^{m}\left(x_{1}\right)=\int_{\underline{\theta}}^{\bar{\theta}} \theta x_{1} d \theta-k x_{1}^{2} / 2-f
$$

The welfare-maximizing affordable price and uniform quality are given by:

$$
x_{1}^{o}=\frac{1+2 \underline{\theta}}{2 k} \text { and } p_{1}^{o}=\underline{\theta} x_{1}^{o}
$$

We assume that the cost of providing quality is high enough to guarantee that this welfare-maximizing quality is lower than $x_{2}$. Thus, we assume $k \geq \underline{k}=\frac{1+2 \underline{\theta}}{2 x_{2}}$.

Unsurprisingly, welfare maximization calls for a higher quality than profit maximization: $x_{1}^{o}>x_{1}^{m}$. Moreover, for the quality $x_{1}^{o}$ sold at price $p_{1}^{o}$ to 
be sustainable, the following firm break-even constraint must be satisfied: $\pi_{1}^{m}\left(x_{1}^{o}\right) \geq 0$ that is

$$
f \leq f_{1}=\frac{4 \underline{\theta}^{2}-1}{8 k}
$$

where $f_{1}<f_{0}$.

Proposition 1 The optimal quality for a postal USO is defined by $x_{1}^{o}$ if $f \leq f_{1}$. Otherwise, for $f_{0}>f>f_{1}$, the optimal quality solves $\pi_{1}^{m}\left(x_{1}\right)=0$ subject to $p_{1}=\underline{\theta} x_{1}$ and $x_{1}=\left[x_{1}^{m}, x_{1}^{o}[\right.$.

Proposition 1 defines the welfare-maximizing quality when the postal technology is the only one available. Our aim is to compare this level of quality with the optimal quality when the postal service and the internet are competing with each other. ${ }^{18}$

\subsection{Designing a postal USO in a competitive environment}

Consider the case in which firms compete and find the welfare-maximizing price-quality pair. As quality is vertically differentiated, firm 2 skims the urban markets but prefers not to serve the unprofitable rural markets (by assumption) so its profit is

$$
\pi_{2}=n(\bar{\theta}-\hat{\theta}) p_{2}
$$

where $\hat{\theta}=\frac{p_{2}-p_{1}}{x_{2}-x_{1}}$ is the indifferent consumer between quality $x_{1}$ at price $p_{1}$ and quality $x_{2}$ at price $p_{2}$.

As a universal service provider, firm 1 has to respect the ubiquity constraint as well as providing an equal quality everywhere. But we allow firm 1 to price discriminate between the monopolistic rural region (price $p_{1}^{r}$ ) and the competitive urban one (price $p_{1}^{u}$ ) as long as the affordability constraint is satisfied. So firm 1's overall profit is:

$$
\pi_{1}=n(\hat{\theta}-\underline{\theta}) p_{1}^{u}+(1-n) p_{1}^{r}-k x_{1}^{2} / 2-f
$$

Equilibrium prices are given by:

$$
p_{1}^{u}=\frac{1-\underline{\theta}}{3}\left(x_{2}-x_{1}\right), p_{2}^{u}=\frac{2+\underline{\theta}}{3}\left(x_{2}-x_{1}\right) \text { and } p_{1}^{r}=\underline{\theta} x_{1} .
$$

\footnotetext{
${ }^{18}$ In Europe, the universal service obligations were defined in a directive dating back to 1997 and most of the Member States have imposed delivery frequency long before the emergence of electronic communications.
} 
At these prices, the affordability constraint is satisfied in the urban region if the quality of the postal service is high enough compared to $x_{2}: p_{i}^{u} \leq p_{1}^{r}$ if $x_{1} \geq x_{2}(1-\underline{\theta}) /(1+2 \underline{\theta})$, and the indifferent consumer is characterized by $\hat{\theta}=\theta^{*}$ where $\theta^{*}=\frac{1+2 \underline{\underline{\theta}}}{3}$.

In the sequel, we will assume that the lower bound of quality for the postal service is defined by $\bar{x}_{1}=x_{2}(1-\underline{\theta}) /(1+2 \underline{\theta})$. This assumption guarantees that, for all $x_{2}$ and $x_{1} \in\left[\bar{x}_{1}, x_{2}\right]$, the market is fully covered at equilibrium prices and that the equilibrium prices defined above are the unique Nash equilibrium in the price game (Wauthy, 1996).

The profits of the firms are given by

$$
\begin{aligned}
& \pi_{1}\left(x_{1}\right)=n\left(\frac{(1-\underline{\theta})^{2}}{9}\left(x_{2}-x_{1}\right)\right)+(1-n) \underline{\theta} x_{1}-k x_{1}^{2} / 2-f \\
& \pi_{2}\left(x_{1}\right)=n\left(\frac{(2+\underline{\theta})^{2}}{9}\left(x_{2}-x_{1}\right)\right)
\end{aligned}
$$

In the duopoly urban market, the turnovers of the firm increase with the degree of product differentiation as long as the market remains fully covered, a standard result.

We assumed that the broadband infrastructure costs was high enough in the rural region, leaving the rural region uncovered by the broadband internet. This non-coverage condition formally writes as follows:

$$
\forall x_{1} \geq \bar{x}_{1},(1-n)\left(\frac{(2+\underline{\theta})^{2}}{9}\left(x_{2}-x_{1}\right)\right)<F
$$

Evaluated at the lowest quality $\bar{x}_{1}$, Equation 5 defines a threshold value for the infrastructure cost $\hat{F}=(1-n) \frac{\underline{\theta}(2+\underline{\theta})^{2}}{3+6 \theta} x_{2}$ such that for any $F \geq \hat{F}$, the infrastructure cannot be financed profitably in the rural region, whatever the quality of postal services.

The welfare is given by

$$
W\left(x_{1}\right)=n\left(\int_{\underline{\theta}}^{\theta^{*}} \theta x_{1} d \theta+\int_{\theta^{*}}^{\bar{\theta}} \theta x_{2} d \theta\right)+(1-n) \int_{\underline{\theta}}^{\bar{\theta}} \theta x_{1} d \theta-k x_{1}^{2} / 2-f
$$

The welfare maximizing quality ${ }^{19}$ is:

$$
\hat{x}_{1}^{o}=\frac{n(1-\underline{\theta})(5 \underline{\theta}+1)+9(1-n)(1+2 \underline{\theta})}{18 k}
$$

\footnotetext{
${ }^{19}$ Notice that, given our assumptions, there is no guarantee that welfare maximizing quality $\hat{x}_{1}^{o}$ satisfies $\hat{x}_{1}^{o} \geq \bar{x}_{1}$. If it would not be the case, the optimal quality would be set at the lowest possible level $\bar{x}_{1}$ and there would be no possibility to adjust the quality downward to satisfy the firms' participation constraint. In the sequel, we assume without loss of generality that the parameters of the model are such that $\hat{x}_{1}^{o} \geq \bar{x}_{1}$.
} 
The welfare maximizing quality trades-off the average value of postal services for the postal users with the cost of providing it. The quality $\hat{x}_{1}^{o}$ is sustainable as long as $\pi_{1}\left(\hat{x}_{1}^{o}\right) \geq 0$. This condition is akin to defining a maximum value $f_{2}$ for the fixed cost. The following Proposition describes the optimal universal service quality in a competitive market.

Proposition 2 In a competitive market, the optimal quality for a postal USO is defined by $\hat{x}_{1}^{o}$ if $f \leq f_{2}$. Otherwise, the optimal quality solves $\pi_{1}\left(x_{1}\right)=0$ and $x_{1} \in\left[\bar{x}_{1}, \hat{x}_{1}^{0}[\right.$.

The consumer's average value for the quality of postal services decreases because the internet skims the high valuation consumers from the urban region. Consequently, the welfare maximizing quality for the universal service unambiguously decreases when the two technologies compete in part of the country: $x_{1}^{o}>\hat{x}_{1}^{o}$. But, as stated in Propositions 1 and 2, the optimal quality is either at the welfare-maximizing level or at the highest sustainable level. Comparison of the welfare-maximizing level is thus not sufficient. We can establish that

Proposition 3 The optimal quality for a postal USO decreases in a competitive market compared to the benchmark case.

This Proposition demonstrates that the emergence of new communication technologies calls for lower quality for the universal postal service. This quality reduction results from a combination of a lower willingness to pay for the quality of postal services and more severe financial constraints in a competitive environment. Indeed, the welfare-maximizing quality trades off consumer willingness to pay and the cost of providing quality. As a proportion of the high-valuation consumers abandon paper communications for digital ones, consumer willingness pay for quality declines while the cost of providing quality is left unchanged. Thus, welfare maximization calls for a reduction of service quality. But on top of that, competition erodes the profits of the postal firm and there are quality levels that were sustainable in the benchmark case that are no longer sustainable under competition. Quality may thus be reduced below the welfare-maximizing level to guarantee the financial viability of the universal service. These two elements concur to lower the optimal quality level in a competitive environment as compared with the benchmark.

The digitalization of the economy calls for a reform of the universal postal service not only motivated by financial constraints. It consists in reducing 
the quality of the service offered (in our case, reducing delivery frequency). Such a reform of the universal service would affect users differently. Clearly, those living in the rural area would certainly be worse off if quality declines as subject to the affordability constraint, welfare increases with quality. The service offered to them has a lower quality and with no option to buy the higher quality one. The impact on those living in the urban area is not clearcut compared to the benchmark case as some use higher quality and others lower service quality. Still, urban consumers are certainly better off than rural ones. Not only they do have access to the high quality technology (the internet) but they are also charged a lower price for postal services. Hence, between the two areas we observe a regional divide which was not present without competition between the two services.

The rapid growth of electronic communications calls for a lightening of the universal postal service. Such a change however does not benefit to all users and, for this reason, it might be politically difficult to implement. More generally, we have considered so far that the universal service was organized and financed on a postal basis exclusively. But with the technologies becoming closer substitutes, one may imagine to broaden the scope of the universal service. The universal service can evolve from a postal service based on paper delivery into mailboxes to a more general communication universal service where both technologies (the internet and the postal sector) contribute to the providing or to financing the service. We consider first a mechanism to share the financial burden of the universal postal service between the two technologies. In this case, the USO is still provided by the postal technology but its financial basis is extended to include the internet. We will consider next, in Section 4, solutions to include the internet in the provision of the universal service.

\subsection{Shared-financing USO}

We first look at the situation where the USO is still provided by the postal operator with the cost shared between the two technologies. Consider that a balanced scheme is set up by the regulator in order to fund the USO. The funding scheme consists of lump sum taxes $\left(t_{1}, t_{2}\right)$ levied on firm 1,2 in the profitable urban market and unitary subsidies $s$ for each rural consumer connected. Hence, for a given unit subsidy $s$ and taxes $t_{i}$, from (2) and (3), profits are now respectively given by $\pi_{2}-t_{2}$ and $\pi_{1}-t_{1}+(1-n) s$. The Nash equilibrium prices remain unchanged and the indifferent consumer is 
not affected by the funding scheme. Therefore profits are now written as

$$
\begin{aligned}
& \hat{\pi}_{1}\left(x_{1}\right)=\pi_{1}\left(x_{1}\right)-t_{1}+(1-n) s \\
& \hat{\pi}_{2}\left(x_{1}\right)=\pi_{2}\left(x_{1}\right)-t_{2} .
\end{aligned}
$$

The universal service fund balancing condition writes $B=t_{1}+t_{2}-(1-n) s \geq$ 0 , and let us define $\left(t^{*}, s^{*}, x_{1}^{*}\right)$ the welfare-maximizing funding scheme that solves the problem

$$
\begin{array}{r}
\max _{t_{1}, t_{2}, s \geq 0, x_{1} \geq \bar{x}_{1}} W\left(x_{1}\right)-B \\
\text { s.t. } \hat{\pi}_{1}\left(x_{1}\right) \geq 0 ; \hat{\pi}_{2}\left(x_{1}\right) \geq 0 \text { and } B \geq 0 .
\end{array}
$$

At the optimum the fund is strictly balanced so that $t_{1}^{*}+t_{2}^{*}=(1-n) s^{*}$. Hence the choice of the optimal quality can be rewritten as $\max _{x_{1}} W\left(x_{1}\right)$ subject to $\pi_{1}\left(x_{1}\right)+\pi_{2}\left(x_{1}\right) \geq 0$. Let $\hat{f}_{2}$ the fixed cost bound for which the optimal quality $\hat{x}_{1}^{o}$ is sustainable with this funding scheme that is $\pi_{1}\left(\hat{x}_{1}^{o}\right)+$ $\pi_{2}\left(\hat{x}_{1}^{o}\right) \geq 0$ whenever $f \leq \hat{f}_{2}$. Thus we can state the following result:

Proposition 4 The optimal quality for a shared-financed USO is defined by $\hat{x}_{1}^{o}$ if $f \leq \hat{f}_{2}$ where $\hat{f}_{2}>f_{2}$. Otherwise, the optimal quality solves $\pi_{1}\left(x_{1}\right)+$ $\pi_{2}\left(x_{1}\right)=0$ and $x_{1} \in\left[\bar{x}_{1}, \hat{x}_{1}^{0}\right.$ [. The quality of the universal service weakly increases compared to the standard competitive case given in Proposition 2.

Clearly, a funding scheme encompassing both the internet and the postal world is a means of relaxing the financial constraint facing the universal service provider hence quality can be improved at the benefit of postal users. This solution is particularly interesting when the optimal quality is not sustainable in a competitive environment i.e. the profits of the postal firm are not large enough to finance the welfare-maximizing quality. In such a case, broadening the tax base is unambiguously welfare-improving provided that taxes are non-distortionary. However, as a funding scheme is to be designed by the regulator, potential informational problems may arise: firms may have incentives to misreport their profits in order to draw informational rents from each others. This may temperate the improving result of the funding scheme.

\section{Communication USO}

In the sequel, we analyze three scenarios to include the internet in the provision of the universal service and not in the financing of a postal USO as 
before. First, we consider an extension of the scope of the USO to include the internet technology. The regulator imposes the ubiquity constraint on the internet firm to foster the deployment of broadband internet in the rural area but it leaves commercial freedom to the internet firm. Second, we consider a more radical change where the universal postal service is dropped out and replaced by a new universal service based on the internet technology. Finally, we study the possibility of combining the postal and the electronic technology to provide universal service. We consider, in particular, the case of hybrid mails where the postal network is used to distribute electronic media to improve the quality of the universal postal service.

\subsection{A broader USO: Ubiquity for the Internet}

To provide high-quality service nationwide, the regulator could enlarge the scope of the USO so as to include both technologies: the postal and the digital ones. Suppose that the regulator defines the universal service as follows. The postal universal service is defined as before by the ubiquity, affordability and uniform quality constraints. In addition, the regulator makes broadband internet available everywhere by imposing the ubiquity constraint on the internet firm. Both technologies are thus available nationwide but pricing constraints are only imposed on the postal product. In this scenario, the regulator defines a complete USO for the postal sector and a lighter version of the USO for the internet.

In this case, the internet firm must deploy its network in the rural area (at cost $F$ ) and it skims the profitable part of both the urban and the rural market. The profits are given by

$$
\begin{aligned}
& \pi_{1}=n\left(\hat{\theta}^{u}-\underline{\theta}\right) p_{1}^{u}+(1-n)\left(\hat{\theta}^{r}-\underline{\theta}\right) p_{1}^{r}-k x_{1}^{2} / 2-f \\
& \pi_{2}=n\left(\bar{\theta}-\hat{\theta}^{u}\right) p_{2}^{u}+(1-n)\left(\bar{\theta}-\hat{\theta}^{r}\right) p_{2}^{r}-F
\end{aligned}
$$

where $\hat{\theta}^{j}=\frac{p_{2}^{j}-p_{1}^{j}}{x_{2}-x_{1}}$ for $j=u, r$. Equilibrium prices are given by: $p_{1}^{u}=p_{1}^{r}=$ $\frac{1-\underline{\theta}}{3}\left(x_{2}-x_{1}\right), p_{2}^{u}=p_{2}^{r}=\frac{\underline{\theta}+2}{3}\left(x_{2}-x_{1}\right)$ and $\hat{\theta}^{j}=\theta^{*}$ in both markets. To satisfy the affordability constraints the price posted by the postal operator must satisfy $p_{1}^{j} \leq \underline{\theta} x_{1}$, implying $x_{1} \geq \bar{x}_{1}$ as in the standard competitive case. The associated profits are

$$
\begin{aligned}
& \tilde{\pi}_{1}\left(x_{1}\right)=\left(\frac{(1-\underline{\theta})^{2}}{9}\left(x_{2}-x_{1}\right)\right)-k x_{1}^{2} / 2-f \\
& \tilde{\pi}_{2}\left(x_{1}\right)=\left(\frac{(2+\underline{\theta})^{2}}{9}\left(x_{2}-x_{1}\right)\right)-F
\end{aligned}
$$


The welfare is given by

$$
\begin{aligned}
\tilde{W}\left(x_{1}\right) & =\int_{\underline{\theta}}^{\theta^{*}} \theta x_{1} d \theta+\int_{\theta^{*}}^{\bar{\theta}} \theta x_{2} d \theta-k x_{1}^{2} / 2-f-F \\
& =W\left(x_{1}\right)+(1-n) \int_{\theta^{*}}^{\bar{\theta}} \theta\left(x_{2}-x_{1}\right) d \theta-F
\end{aligned}
$$

The corresponding welfare maximizing quality is equal to:

$$
\tilde{x}_{1}^{o}=\frac{(1-\underline{\theta})(5 \underline{\theta}+1)}{18 k}
$$

Again, this quality trades-off the utility of postal users with the cost of providing the service. It is immediate that $\tilde{x}_{1}^{o}<\hat{x}_{1}^{o}$ since $\tilde{x}_{1}^{o}=\hat{x}_{1}^{o}-\frac{1-n}{18 k}(2+$ $\underline{\theta})(4+5 \underline{\theta})$. The quality imposed on the postal firm is lower when the internet is available everywhere because consumer willingness to pay for postal services is lower.

Let $\tilde{f}_{2}$ and $\tilde{F}$ respectively the fixed cost bound and the infrastructure cost for which the welfare-maximizing quality $\tilde{x}_{1}^{o}$ is sustainable when the ubiquity constrained is imposed for the internet which means that $\tilde{\pi}_{1}\left(\tilde{x}_{1}^{o}\right) \geq 0$ and $\tilde{\pi}_{2}\left(\tilde{x}_{1}^{o}\right) \geq 0$.

Proposition 5 The optimal quality with internet ubiquity is defined by $\tilde{x}_{1}^{o}$ if $f \leq \tilde{f}_{2}$ and $F<\tilde{F}$. Otherwise, the optimal quality alternatively solves $\tilde{\pi}_{1}\left(x_{1}\right)=0$ or $\tilde{\pi}_{2}\left(x_{1}\right)=0$ and $x_{1} \in\left[\bar{x}_{1}, \tilde{x}_{1}^{O}[\right.$. The quality of the universal service decreases compared to the standard competitive case given in Proposition 2.

Wider broadband penetration implies a reduction of the optimal quality for the universal postal service. As before, quality reduction is motivated by a lower willingness to pay as high valuation consumers switch to the internet and by financial constraint. When the internet is made available everywhere, high valuation users in both regions switch to the digital technology. The willingness to pay for the quality of postal service thus declines and the welfare-maximization calls for a lighter postal USO. In addition, nationwide coverage of the internet erodes the profits of the postal firm compared to the benchmark case and quality might be reduced further to meet the sustainability constraint of the postal operator. More precisely, the sustainability constraint imposed on the postal firm is stronger in this broader USO scenario i.e. for all relevant quality $x_{1}, \pi_{1}\left(x_{1}\right)>\hat{\pi}_{1}\left(x_{1}\right)$ implying $\hat{f}_{2}<f_{2}$. Thus there are quality levels that were sustainable in the benchmark case but that can no longer be sustained when the internet is ubiquitous. 
Finally, quality might be reduced further to increase the profit of the internet firm in order to make the financing of the infrastructure feasible. Indeed, by the principle of maximum differentiation, the firms' profit increases when the quality differential increases. We have assumed that the profits on the rural markets alone were insufficient to cover the infrastructure cost (Equation 5). If the internet firm is not able to self-finance the infrastructure cost with its total profit, reducing $x_{1}$ i.e. reducing competitive pressures might be necessary to reach budget balance.

Finally notice that this policy is not sustainable if $\tilde{\pi}_{2}\left(\bar{x}_{1}\right)<0$. The equation $\tilde{\pi}_{2}\left(\bar{x}_{1}\right)=0$ defines an upper-bound $\tilde{F}=\frac{\underline{\theta}(2+\underline{\theta})^{2}}{3+6 \underline{\theta}} x_{2}$ for the infrastructure cost above which the deployment of infrastructure in the rural area cannot be assured profitably i.e. total profits of the internet are too low to finance the infrastructure cost in the rural area. In such a case, imposing the ubiquity constraint to the internet is not possible without public funding.

\subsection{Changing technology: Internet USO}

As a second option, suppose that the regulator keeps the same definition for the universal service: ubiquity, affordability and uniform quality, but changes the technology used to deliver it. The USO are shifted from the postal operator to the internet. The postal operator is thus relieved from the universal service obligations and the USO are imposed on the internet. In such a case, firm 2 has to offer internet services in both regions, implying a connection cost $F$, at the affordable rate $p_{2}^{j} \leq \underline{\theta} x_{2}$. The postal firm is no longer obliged to deliver uniform quality or even operate nationwide. Participation of the postal firm becomes an issue. In our model, should firm 1 be active on at least one market, it must support the fixed cost $f$.

Depending on the participation decision of firm 1 , market $j=u, r$ is either monopolized by the internet firm supplying services at the affordable price or a duopoly market with the two technologies competing. We first analyze the equilibrium in a duopoly configuration and later check the conditions for (1) participation of the postal firm and (2) sustainability of the internet USO option.

When firms compete on market $j$, the equilibrium prices are the solution of

$$
\begin{array}{r}
\max _{p_{1}^{j}} n^{j}\left(\hat{\theta}^{j}-\underline{\theta}\right) p_{1}^{j}-k^{j}\left(x_{1}^{j}\right)^{2} / 2 \\
\max _{p_{2}^{j}} n^{j}\left(\bar{\theta}-\hat{\theta}^{j}\right) p_{2}^{j} \quad \text { subject to } p_{2}^{j} \leq \underline{\theta} x_{2}
\end{array}
$$


Define $x_{1}^{*}=2 x_{2} \frac{1-\theta}{2+\theta}$ with $\left.x_{1}^{*} \in\right] \bar{x}_{1}, x_{2}$ [. If the quality of the postal firm in region $j$ is larger than $x_{1}^{*}$, the solution to the above problem is given by: $p_{1}^{j}=\frac{1-\underline{\theta}}{3}\left(x_{2}-x_{1}^{j}\right), p_{2}^{j}=\frac{\theta+2}{3}\left(x_{2}-x_{1}^{j}\right)$ and $\hat{\theta}^{j}=\theta^{*}$. The condition $x_{1}^{j} \geq x_{1}^{*}$ is nothing but the condition that guarantees that the unconstrained equilibrium price $p_{2}^{j}$ satisfies the affordability constraint.

If $x_{1}^{j}<x_{1}^{*}$, then the unconstrained equilibrium price of the internet firm is no longer affordable implying that $p_{2}^{j}=\underline{\theta} x_{2}$ to satisfy the USO. Given $p_{2}^{j}$, the profit maximizing price of firm 1 is given by $p_{1}^{j}=\underline{\theta} x_{1}^{j} / 2$.

The profit of firm 1 at equilibrium prices when it supplies a quality $x_{1}^{j}$ is equal to

$$
\pi_{1}^{j}\left(x_{1}^{j}\right)=\left\{\begin{array}{llr}
\frac{1}{4} \frac{n^{j} \underline{\theta}^{2}}{x_{2}-x_{1}^{j}}\left(x_{1}^{j}\right)^{2}-\frac{1}{2} k^{j}\left(x_{1}^{j}\right)^{2} & \text { if } & x_{1}^{j} \in\left[\bar{x}_{1}, x_{1}^{*}\right] \\
\frac{(1-\underline{\theta})^{2}}{9}\left(x_{2}-x_{1}^{j}\right)-\frac{1}{2} k^{j}\left(x_{1}^{j}\right)^{2} & \text { if } & x_{1}^{j} \in\left[x_{1}^{*}, x_{2}\right]
\end{array}\right.
$$

From that, we can establish the following:

Lemma 1 If the postal firm is active on market $j=u, r$, then it supplies the quality $x_{1}^{j}=x_{1}^{*}$.

Here two forces are at play when imposing an affordability constraint on the internet firm. When the low quality $x_{1}$ is close enough to the high quality $x_{2}$, competition is sufficiently fierce to allow the internet operator to set prices that are affordable at equilibrium. As a result, when choosing its quality, the postal firm wants to relax competition by reducing $x_{1}$-a standard application of the principle of maximum differentiation-. Higher product differentiation raises prices and profits but, in the internet USO scenario, the internet firm cannot raise its price above the affordable level. If products become sufficiently differentiated, the affordability constraint is binding changing the nature of competition between firms. Firm 2 no longer reacts to a quality decrease by a price increase. Without this price reaction, reducing quality of postal services implies loosing market shares unless compensated by a sufficiently large price cut. For these reasons, firm 1 has no incentives to increase product differentiation when the affordable price constraint is binding. The universal service modifies the nature of competition implying that the optimal quality is defined as $x_{1}^{*}$.

Having defined the equilibrium prices and quality, we now turn to the participation decision of firm 1 . Firm 1 will be active in region $j$ at two conditions. First, the operating profit in that region must be positive $\pi_{1}^{j}\left(x_{1}^{*}\right) \geq 0$. If firm 1 is making losses on market $j$, it is better off withdrawing from this market leaving the internet firm as a constrained monopolist. As we 
assumed that $k^{u} / n>k^{r} /(1-n)$, we have $\pi_{1}^{u}\left(x_{1}^{*}\right) \geq \pi_{1}^{r}\left(x_{1}^{*}\right)$ and thus the postal firm will never cover the rural region exclusively. As a matter of fact, we can establish that, given our parameter restrictions, the postal firm will not cover the rural area when the internet must do so as part of the USO.

Lemma 2 In the internet USO scenario, the postal firm will not be active in the rural region.

The two markets cannot be served profitably by the postal firm in the internet USO scenario. With an internet universal service, the postal firm leaves out the low profitability market that will be served by the internet firm exclusively. Having said that, nothing guarantee at this stage that the postal firm will be active in the urban region. The second condition for participation is that the total operating profits in the urban market must be large enough to cover the fixed cost $f$. Firm 1 will serve the urban market if $\pi_{1}^{u}\left(x_{1}^{*}\right) \geq f$. This equation defines a fixed cost threshold $f^{u}$ and for $f>f^{u}$, both markets will be monopolized by the internet firm and the service will be provided at the affordable rate. To summarize we have

Proposition 6 (1) The postal firm is not active in the rural region. (2) If $f \leq f^{u}$, the postal firm is active in the urban region supplying quality $x_{1}^{*}$.

In this scenario however, profits made by the internet might be insufficient to finance network extension to the rural area. With the internet offered at the affordable rate and the two markets monopolized by firm 2 $\left(f>f^{u}\right)$, the firm is able to recover its infrastructure cost if:

$$
\underline{\theta} x_{2} \geq F
$$

This condition defines a critical value $\bar{F}=\underline{\theta} x_{2}$. Should the infrastructure cost exceed this threshold, the internet USO cannot be sustained without public subsidies. Internet USO is a mean to deliver high quality nationwide but this scenario may not be self-funded. ${ }^{20}$ If the postal firm is active in the urban market $\left(f<f^{u}\right)$ supplying quality $x_{1}^{*}$, a fraction $\left(\theta^{*}-\underline{\theta}\right)$ of the

\footnotetext{
${ }^{20}$ In Finland, the government has launched a broadband project to connect all citizens, including those living in sparsely-populated areas, to the Internet with fast fibre-optic or cable networks by 2015. The government has decided to make a $100 \mathrm{Mbit} / \mathrm{s}$ broadband connection a legal right by the end of 2015 and connections should be offered at a reasonable price. It is expected that telecommunication operators will construct fast connections in densely-populated areas. Public funding will be provided to projects that are not commercially viable in sportily populated areas. More than 100 million euros of public subsidies will be necessary to carry out this project.
} 
urban market still uses the postal technology and the profit of the internet firm is:

$$
\left[n \frac{2(1-\underline{\theta})}{3}+(1-n)\right] \underline{\theta} x_{2}-F
$$

From this equation, we can define a fixed cost threshold $\overline{\bar{F}}=\left[n \frac{2(1-\underline{\theta})}{3}+(1-\right.$ $n)] \underline{\theta} x_{2}<\bar{F}$ and for $F \leq \overline{\bar{F}}$, deploying infrastructure in the rural area cannot be realized without public subsidies.

\subsection{Technological mixed USO: Hybrid mail}

In the previous two scenarios, the internet was supposed to be perfectly substitutable to the postal service in order to ensure the communication USO. However for some technical or legal reasons and persistent habits, it can occur that traditional mail cannot be fully replaced by electronic mail.

In this section, we consider hybrid mail which is delivered using a combination of electronic and physical delivery. Hybrid mail is prepared electronically, printed out and converted to a physical letter that is distributed into mailboxes. There already exists hybrid mail platforms for registered mail, for commercial mails and for postcards and greeting cards prepared on a smartphone, and this type of mail is likely to expand in future. By combining the two technologies, hybrid mail can be used to provide higher quality service at a lower cost, especially in the rural region.

Let us assume that the regulator keeps the same definition for the universal service -ubiquity, affordability and uniform quality- but mixes the technologies to deliver the universal service. However, in order to avoid the caveats highlighted with the Internet USO situation, the US provider remains the postal provider. Thus, there is no need to deploy the internet infrastructure in the rural area at a high cost since the digital technology is used upstream to prepare the mail but not for its delivery.

Hybrid mail is a technological mix between the postal service and the internet, the quality of which depends on that of the two components. Let us denote the quality of hybrid mail by $y$ and assume that $y=\phi\left(x_{2}, x_{1}\right)$ where $\nabla \phi\left(x_{2}, x_{1}\right)>0$, with $\phi(0,0)=0$ and $\phi\left(x_{2}, x_{1}\right) \leq x_{2}$ for all $x_{1} \leq x_{2}$. For the sake of simplicity and tractability we assume a linear technology $\phi\left(x_{2}, x_{1}\right)=\alpha x_{2}+x_{1}$ where the hybridity parameter $\alpha$ is exogenously picked up in $] 0, \alpha^{o}$ [; the upper bound $\alpha^{o}$ guarantying that $y<x_{2}$ for all admissible values of $x_{1}$.

For hybrid mail, all the upstream activities (preparation, collection and sorting) are performed electronically but delivery to mailboxes remains clas- 
sical. The costs of the delivery network thus are left unchanged. Upstream activities are performed by commercial firms for a unit price $a \geq 0$ and we will assume, without loss of generality, that $a=0$. In our formulation, hybrid mail enables the postal operator to deliver a quality postal service at a lower cost.

Firms compete on the urban markets and the postal operator is the only service provider in the rural ones. The competitive setting is very close to our standard competitive case up to the quality mix. And some regular analogies can be derived. Profits are now given by:

$$
\begin{aligned}
& \pi_{2}=n(\bar{\theta}-\hat{\theta}) p_{2}, \\
& \pi_{1}=n(\hat{\theta}-\underline{\theta}) p_{1}^{u}+(1-n) p_{1}^{r}-k x_{1}^{2} / 2-f,
\end{aligned}
$$

where $\hat{\theta}=\frac{p_{2}-p_{1}}{x_{2}-y}=\frac{p_{2}-p_{1}}{(1-\alpha) x_{2}-x_{1}}$ is the now indifferent consumer between quality $y$ at price $p_{1}$ and quality $x_{2}$ at price $p_{2}$.

Equilibrium prices are given by:

$\check{p}_{1}^{u}=\frac{1-\underline{\theta}}{3}\left((1-\alpha) x_{2}-x_{1}\right), \check{p}_{2}^{u}=\frac{\underline{\theta}+2}{3}\left((1-\alpha) x_{2}-x_{1}\right)$ and $\check{p}_{1}^{r}=\underline{\theta}\left(\alpha x_{2}+x_{1}\right)$.

and these prices satisfy the affordability constraint for all $x_{1} \geq \bar{x}_{1}$. Hybrid mail is cheaper than traditional mail in the urban area because its improved quality is more than compensated by increased competition between the two products that are closer substitutes. For the same reason, the internet is also cheaper. In the rural area, hybrid mail is more expensive than traditional mail because the improved quality is not compensated by a market competition effect.

The equilibrium profits of the firms and are given by

$$
\check{\pi}_{1}\left(x_{1}\right)=\pi_{1}\left(x_{1}\right)+H \alpha x_{2} \quad \text { and } \quad \check{\pi}_{2}\left(x_{1}\right)=\pi_{2}\left(x_{1}\right)-\frac{n}{9}(2+\underline{\theta})^{2} \alpha x_{2}
$$

where $H=(1-n) \underline{\theta}-n(1-\underline{\theta})^{2} / 9$. One can directly see that hybrid mail is dissipating the profit of the internet provider due to increased competition, i.e. $\check{\pi}_{2}\left(x_{1}\right) \leq \pi_{2}\left(x_{1}\right)$. For the incumbent, the improved technology has two opposite effects. On the one hand, competition on the urban market is exacerbated because products are closer substitutes. On the other hand, the postal operator delivers higher quality and it can value that on the rural market. Formally, if $H \leq 0$, the postal firm has a lower profit for any 
delivery frequency $x_{1}$. This condition holds true if $n \geq \check{n}=9 \underline{\theta} /\left(7 \underline{\theta}+\underline{\theta}^{2}+1\right)$ i.e. when urban market is large.

By linearity assumed for hybrid mail technology, the welfare can be written as

$$
\check{W}\left(x_{1}\right)=W\left(x_{1}\right)+\left[n \int_{\underline{\theta}}^{\hat{\theta}} \theta d \theta+(1-n) \int_{\underline{\theta}}^{\bar{\theta}} \theta d \theta\right] \alpha x_{2}
$$

so that the maximizing postal quality is still given by (6) so $\check{x}_{1}^{o}=\hat{x}_{1}^{o}$. The optimal quality for the postal service included in hybrid mails is equal to the standard competitive one. Given this delivery frequency, the quality of the hybrid mail is $\check{y}=\alpha x_{2}+\hat{x}_{1}^{o}$ which is sustainable if $f \leq \check{f}_{2}$ where $\check{f}_{2}$ solves $\check{\pi}_{1}\left(\hat{x}_{1}^{o}\right)=0$. If $f>\check{f}_{2}$, the optimal postal quality solves $\check{\pi}_{1}\left(x_{1}\right)=0$. We now state the following result:

Proposition 7 If $n \leq \check{n}$, the quality of the postal service is identical to the quality delivered in the benchmark case for $f<f_{2}$ and strictly higher for $f>f_{2}$. If $n>\check{n}$, the quality of postal service is identical to the quality delivered in the benchmark case for $f<\check{f}_{2}$ and strictly lower for $f \geq \check{f}_{2}$.

Proposition 7 highlights the impact of embodying electronic technologies in the postal world. The impact of the shared technology on the quality of postal services cannot be unambiguously assessed as it depends on whether the technological improvement increases or decreases profit. Indeed, with hybrid mails, competition between services is intensified in the urban market while the postal firm can value the higher quality service by charging higher prices in the rural market. Depending on which effect dominates, the quality of postal service will be higher or lower compared to the competitive case.

In this scenario, the quality of the product depends on the quality of the physical delivery network but also on the hybridity parameter. If the latter is high enough, service quality will be improved even if the postal network adopts a lower delivery frequency i.e. the electronic technology more than compensate the possible decline in the quality of postal services.

\section{Comparisons}

We have presented and specified four scenarios where the universal service provision or its financing is shared between the postal and the internet technology. Our aim in this section is to compare these four alternatives with a particular focus on the quality of postal services, the broadband penetration, the need for public funding and the welfare. Our reference point 
for these comparisons is the reformed universal service that is optimal in a competitive environment. Comparisons are summed up in Table 2.

\subsection{The quality of postal services}

We have already established in Propositions 4 and 5 that the optimal quality of postal services is weakly higher in the shared financing case and lower in the ubiquity internet case compared to the competitive benchmark. These two reforms have the same goal -increasing the quality offered in the rural area- but different means. The funding scheme aims at providing a postal service of higher quality by broadening its financial base. With the second scenario, higher quality in the rural area is achieved by imposing a national coverage for the internet. But by doing so, both the willingness and the ability to pay for postal service decrease and the universal service should be adapted accordingly.

Comparison of quality with the internet USO case is more complex. First, the postal firm is no longer present in the rural markets and participation in the urban markets is conditional. The internet USO may thus drive out the postal technology for the market in which case comparing qualities becomes irrelevant. Second, imposing USO on the internet firm limits the possibility of gaining profit by increasing product differentiation because the internet firm cannot price above the affordable level. For these reasons, it is not possible to unambiguously assess whether quality is higher or lower than in the competitive benchmark case.

Finally if the postal operator combines postal and electronic technologies, postal quality is maintained, increased or decreased compared to the benchmark case, depending on the impact of intensified competition on the profits. But in this scenario, the postal quality is only a component of the product quality. And the latter could increase even if the postal quality declines.

\subsection{Broadband penetration and the need for public funds}

The issue of broadband penetration is a policy target that has been tackled in two scenarios: Ubiquity for the Internet and Internet USO. We have started our analysis by assuming that infrastructure costs were so high in the rural area $(F>\hat{F})$ meaning that commercial firms will never cover this region unless they are forced to. Casual evidence confirms such a regional divide between well-connected urban areas and poorly-connected rural ones and this regional divide is likely to persist with the deployment of next 
generation access networks. Imposing a ubiquity constraint on the internet seems to be the only possible way of reaching full broadband coverage.

In the benchmark case, only a fraction $\left(\bar{\theta}-\theta^{*}\right)$ of the urban population uses the internet. The broadband penetration is $n\left(\bar{\theta}-\theta^{*}\right)=n(2+\underline{\theta}) / 3$. When the ubiquity constraint is imposed, a fraction $\left(\bar{\theta}-\theta^{*}\right)$ of the rural population uses the internet and the broadband penetration increases to $(2+\underline{\theta}) / 3$. When, in addition, the internet service is offered at the affordable rate, broadband penetration can reach up to $100 \%$ depending on whether the postal operator remains active or not. But, a larger broadband penetration cannot be achieved at no cost. As already mentioned, installing broadband infrastructure may require public funding. The need for public fund can be represented by the thresholds $\tilde{F}, \bar{F}$ and $\overline{\bar{F}}$.

It can be easily shown that $\hat{F}<\tilde{F}$. This means that there exist values of the infrastructure cost for which imposing the ubiquity constraint on the internet can be realized without the need for public subsidies. For $F \in$ $[\hat{F}, \tilde{F}]$, profits in the urban area are large enough to subsidy the expansion of broadband connections in the rural area. ${ }^{21}$.

Conditions for the internet USO to be sustainable without public subsidies are unsurprisingly stronger. The threshold $\bar{F}$ is always below $\tilde{F}$ and,

eventually, $\bar{F}$ could be smaller than $\hat{F}$; It will be the case if $n<\frac{3+\underline{\theta}^{2}}{(2+\underline{\theta})^{2}}$. If $\bar{F} \leq \hat{F}$, it is not possible to have an internet USO without the support of public funds. Conversely, if $\bar{F}>\hat{F}$, there might be value of the infrastructure cost for which the internet USO is self-supporting.

\section{$5.3 \quad$ Welfare}

In terms of welfare, there is no clear-cut ranking of the different alternatives as this depends on many parameters including the cost of public funds. However, we can check whether the policy detailed in the context of a communication USO are welfare-improving compared to the competitive postal USO case.

First, compared to the competitive benchmark, the shared-financing of the universal service is clearly welfare improving. The universal service fund relaxes the financial constraints and allows the postal firm to deliver higher quality, as shown in Proposition 4. Furthermore, due to higher quality, prices in the urban area are lower. Thus, as long as taxes are non-distortionary, the creation of a large base universal service fund to finance the universal postal service enhances the welfare.

\footnotetext{
${ }^{21}$ But this result may not be true if several infrastructure compete in the urban area.
} 
Second, using (7), the welfare difference for the ubiquity internet policy can be expressed as:

$$
\tilde{W}\left(\tilde{x}_{1}^{o}\right)-W\left(\hat{x}_{1}^{o}\right)=\left[W\left(\tilde{x}_{1}^{o}\right)-W\left(\hat{x}_{1}^{o}\right)\right]+(1-n) \int_{\theta^{*}}^{\bar{\theta}} \theta\left(x_{2}-x_{1}\right) d \theta-F
$$

the first term is negative and measures the impact in terms of welfare of a lower quality of postal service. The second term is positive and measures the welfare impact of providing the internet service in the rural area, the last term is the infrastructure cost of bringing the internet to that region. ${ }^{22}$ From that the impact of a ubiquity internet policy cannot be unambiguously assessed.

Third, comparing the internet USO situation is more difficult because there are different market scenarios. Suppose that the postal cannot operate profitably $\left(f>f^{u}\right)$, the welfare can be defined as:

$$
W\left(x_{2}\right)=\int_{\underline{\theta}}^{\bar{\theta}} \theta x_{2}-F
$$

Changing the USO provider has the following impacts on welfare

$W\left(x_{2}\right)-W\left(\hat{x}_{1}^{o}\right)=n \int_{\underline{\theta}}^{\theta^{*}} \theta\left(x_{2}-\hat{x}_{1}^{o}\right) d \theta+(1-n) \int_{\underline{\theta}}^{\bar{\theta}} \theta\left(x_{2}-\hat{x}_{1}^{o}\right) d \theta-F+f+k\left(\hat{x}_{1}^{o}\right)^{2} / 2$

The first two terms are the benefits in term of quality enhancing for consumers. The third term is the cost of infrastructure and the last terms are the cost saving of not using the postal service. Again the global impact is ambiguous.

Last, for the hybrid mail using (10), it is obvious that the welfare impact is positive if the quality of postal service does not decline (see conditions in Proposition 5). If it does, welfare might still be superior depending on the hybridity parameter.

Table 2 summarizes our discussion.

\section{Concluding remarks}

In this paper, we have shown that, the emergence of electronic communications calls for a reform of the universal postal service. Accordingly, in a

\footnotetext{
${ }^{22}$ If the internet cannot self finance the deployment of infrastructure in the rural region, this cost must include the cost of public funding.
} 


\begin{tabular}{|l|c|c|c|c|}
\hline & $\begin{array}{c}\text { Coverage } \\
\text { internet }\end{array}$ & $\begin{array}{c}\text { Postal } \\
\text { quality }\end{array}$ & $\begin{array}{c}\text { Need for } \\
\text { Public Fund }\end{array}$ & Welfare \\
\hline Shared financing USO & $\mathrm{u}$ & + & No & + or $=$ \\
Ubiquity for internet & $\mathrm{u}$ and $\mathrm{r}$ & - & Likely & $?$ \\
Internet USO & $\mathrm{u}$ and $\mathrm{r}$ & $?$ & Very likely & $?$ \\
Techno. Mix & $\mathrm{u}$ & + & No & + \\
\hline
\end{tabular}

Table 2: Comparisons with the competitive case

competitive environment, the universal service should be lightened and it calls for a reduction of the service quality. In the postal case, it means to provide a service with lower delivery frequency. It is often mentioned that the universal service constraint should be relaxed because increased competition reduces the possibility of financing the USO. In this paper, we have shown that the primary reason for reforming the USO is evolving consumption habits and an associated lower willingness to pay for the service. In addition to that, financial constraints may require a reform on a larger scale.

A lower quality universal service combined with the emergence of new products would not be beneficial to all. Clearly those who do not have access to the internet are worse-off because they do not have the option to switch to the new technology while the existing one is downgraded. For this reason, we believe that the reform of the postal USO cannot be envisioned by focusing on the postal sector exclusively but rather that it must encompass the new technology sector, either as a source of financing, a possible universal service provider or as a technology provider. We thus have examined four possible reforms of the universal service that include both technologies. Such a communication USO does not necessarily enhance the welfare for two reasons. First, imposing a larger deployment of broadband infrastructure in the areas where it cannot be self-financed may require the use of public fund. Second, changing the USO has an impact on the competition between firms and technologies. A lower postal quality for instance relaxes the price competition and leads to higher prices.

This paper has discussed the quality in terms of delivery speed, for which the internet has an uncontested advantage. There are yet other dimensions to quality -security, reliability and ease of use- and integrating those in the model appears a new challenge for future research. 


\section{References}

[1] Alleman, J., P. Rappoport and A. Banerjee (2010). Universal Service: A New Definition?, Telecommunications Policy, 34(1-2), 86-91.

[2] Ambrosini, X., Boldron F. and Roy B., (2006). Universal Service Obligation in the Postal Sector: Economic Learnings from Cross-Country Comparisons, in M. A. Crew a P. R. Kleindorfer (eds), Progress toward Liberalization of the Postal and Delivery Sector, Springer, New-York, US.

[3] Billón, M., Marco, R. and F. Lera-López (2009). Disparities in ICT Adoption. A Multidimensional Approach to Study the Cross-Country Digital Divide, Telecommunications Policy, 33(10-11), 596-610.

[4] Boldron F., Joram D., Martin L. and Roy B., (2007). From Size of the Box to the Costs of Universal Service Obligation: A Cross-Country Comparison, in M. A. Crew and P. R. Kleindorfer (eds), Liberalization of the Postal and Delivery Sector, Edward Elgar, Cheltenham, UK.

[5] Bouckaert, J., van Dijk, T. and F. Verboven (2010). Access Regulation, Competition, and Broadband Penetration: An International Study, Telecommunications Policy, 34(11), 661-671.

[6] Calzada, J. (2009). Universal Service Obligations in the Postal Sector: The Relationship between Quality and Coverage, Information Economics and Policy, 21(1), 10-20.

[7] Cremer, H., Gasmi, F., Grimaud, A. and J.-J. Laffont (2001). Universal Service: An Economic Perspective, Annals of Public and Cooperative Economics, 72(1), 5-43.

[8] Crew, M. A. and P. R. Kleindorfer (2005). Competition, Universal Service and the Graveyard Spiral. in M. A. Crew a P. R. Kleindorfer (eds), Regulatory and Economics Changes in the Postal and Delivery Sector, Kluwer Academic Press, Boston, US.

[9] Crew, M. A. and P. R. Kleindorfer (2006). Approaches to the USO under Entry, in Crew, M. A. and P. R. Kleindorfer (eds) Liberalization of The Postal And Delivery Sector, Edward Elgar, Cheltenham, UK.

[10] Gautier, A. and D. Paolini (2011). Universal Service Financing in Competitive Postal Markets: One Size Does not Fit All, Review of Network Economics, 10(3), Art. 6. 
[11] Gautier, A. and X. Wauthy (2012). Competitively Neutral Universal Service Obligations. Information Economics and Policy, 24(3-4), 254261.

[12] Gideon, C. and D. Gabel (2011). Disconnecting: Understanding Decline in Universal Service, Telecommunications Policy, 35(8), 737-751.

[13] Jaag, C. and U. Trinkner (2011). The Future of the USO - Economic Rationale for Universal Services and Implications for a Future-Oriented USO, Swiss Economics Working Paper 26, Zürich, Switzerland.

[14] Schuster, P. (2013). One for All and All for One: Privatization and Universal Service Provision in the Postal Sector, Applied Economics, 45(26), 3667-3682.

[15] Wauthy, X. (1996). Quality Choice in Models of Vertical Differentiation, Journal of Industrial Economics, 44(3), 345-353.

\section{Appendix.}

Proof of Proposition 1 Derivating $W^{m}\left(x_{1}\right)$ w.r.t to $x_{1}$ and solving leads to $x_{1}^{o}$. Let $f=f_{1}$ defined in (1) be the fixed cost value for which $\pi_{1}^{m}\left(x_{1}^{o}\right)=0$.

As $x_{1}^{m}<x_{1}^{o}$, then for $f_{0}>f>f_{1}$, the optimal quality $x_{1}$ solves the break-even equation $\pi_{1}^{m}\left(x_{1}\right)=0$ i.e. $x_{1}=x_{1}^{m}(f)=(\underline{\theta}+\sqrt{\underline{\theta}-2 f k}) / k$ and it yields necessarily $x_{1}^{m}<x_{1}^{m}(f)<x_{1}^{o}$. Notice that by concavity of the profit function, the optimal quality decreases with $f$, for $f<f_{1}$.

Proof of Proposition 2 Derivating $W\left(x_{1}\right)$ w.r.t to $x_{1}$ and solving leads to $\hat{x}_{1}^{o}$. This quality $\hat{x}_{1}^{o}$ is sustainable iff $\pi_{1}\left(\hat{x}_{1}^{o}\right) \geq 0$. This break-event point equivalently defines a threshold value $f_{2}$ for the fixed cost such that for $f \leq f_{2}$, the welfare maximizing quality is sustainable.

When $\hat{x}_{1}^{o}$ is not sustainable $\left(f>f_{2}\right)$, the optimal quality $x_{1}(f)$ solves $\pi_{1}\left(x_{1}(f)\right)=0$. Given that $\operatorname{argmax}_{x_{1}} \pi_{1}\left(x_{1}\right)<\hat{x}_{1}^{o}$, it is necessary that $x_{1}(f)<\hat{x}_{1}^{o}$. Furthermore, $x_{1}(f)$ decreases with $f$ by concavity of the profit function.

Proof of Proposition 3 Under the assumption of fully covered markets, the prices satisfy $p_{1}^{u} \leq p_{1}^{r}$ and the profits of the postal firm unambiguously decline with competition: $\forall x_{1} \geq \bar{x}_{1}, \pi_{1}^{m}\left(x_{1}\right)>\hat{\pi}_{1}\left(x_{1}\right)$. Thus a quality level that is sustainable in the competitive case is also sustainable in the benchmark case. 
Suppose that the quality $x_{1}^{o}$ is sustainable in the benchmark case $(f \leq$ $f_{1}$ ). Then, given that the welfare-maximizing quality in the competitive case is at most $\hat{x}_{1}^{o}$ which is smaller than $x_{1}^{o}$, the proof is obvious.

Suppose next that $f>f_{1}$. The quality in the benchmark case is given by $x_{1}(f)$ defined above. But this quality is not sustainable in the competitive case as $\pi_{1}^{m}\left(x_{1}(f)\right)=0>\hat{\pi}_{1}\left(x_{1}(f)\right)$. Thus quality in the competitive case is necessarily smaller than $x_{1}(f)$. Consequently this implies that $f_{2}<f_{1}$.

Proof of Proposition 4. Given that $\pi_{2}\left(x_{1}\right)$ is strictly positive for all possible qualities in the range $\left[\bar{x}_{1}, x_{2}\left[\right.\right.$, the threshold value $\hat{f}_{2}<f_{2}$. We thus have:

- For $f \leq \hat{f}_{2}$, the quality is equally set to $\hat{x}_{1}^{o}$ in both scenarios.

- For $\hat{f}_{2}<f \leq f_{2}$, the quality $\hat{x}_{1}^{o}$ is sustainable in the shared financing case but not in the standard competitive case. Quality is thus strictly higher with the funding scheme as $\hat{x}_{1}^{o}>x_{1}(f)$.

- For $f_{2}<f$, the quality is given by the sustainability constraint in both scenarios. Given that $\pi_{1}\left(x_{1}\right)$ and $\pi_{2}\left(x_{1}\right)$ are both decreasing in $x_{1}$ and $\pi_{2}\left(x_{1}\right)>0$, it is obvious that the sustainable quality is higher in the shared financing scenario.

Proof of Proposition 5. Derivating $\tilde{W}\left(x_{1}\right)$ w.r.t to $x_{1}$ and solving leads to $\tilde{x}_{1}^{o}$. It is obvious from the definition of $\tilde{W}\left(x_{1}\right)$ in Equation 7 that $\tilde{x}_{1}^{o}<\hat{x}_{1}^{o}$. The quality $\tilde{x}_{1}^{o}$ is sustainable iff $\tilde{\pi}_{1}\left(\tilde{x}_{1}^{o}\right) \geq 0$ and $\tilde{\pi}_{2}\left(\tilde{x}_{1}^{o}\right) \geq 0$ this can be written as $f \leq \tilde{f}_{2}$ and $F \leq \tilde{F}$ where

$$
\tilde{f}_{2}=\frac{(1-\underline{\theta})^{2}}{9}\left(x_{2}-\tilde{x}_{1}^{o}-\frac{1}{72} \frac{(5 \underline{\theta}+1)^{2}}{k}\right) \text { and } \tilde{F}=\frac{(2+\underline{\theta})^{2}}{9}\left(x_{2}-\tilde{x}_{1}^{o}\right)
$$

It can be shown that $\tilde{\pi}_{1}\left(x_{1}\right) \leq \pi_{1}\left(x_{1}\right)$ for all $x_{1} \geq \bar{x}_{1}$. Indeed, the difference states as

$$
\tilde{\pi}_{1}\left(x_{1}\right)-\pi_{1}\left(x_{1}\right)=(1-n)\left(\frac{(1-\underline{\theta})^{2}}{9}\left(x_{2}-x_{1}\right)-\underline{\theta} x_{1}\right),
$$

This difference is a decreasing function of $x_{1}$ and equals to zero for $x_{1}=$ $x_{2} \frac{(1-\underline{\theta})^{2}}{1+\underline{\theta}^{2}+7 \underline{\theta}}$. But this value is smaller than $\bar{x}_{1}$, implying $\tilde{\pi}_{1}\left(x_{1}\right)-\pi_{1}\left(x_{1}\right)<0$ for all $x_{1} \in\left[\bar{x}_{1}, x_{2}\right]$.

Consequently, we have that $\tilde{f}_{2}<f_{2}$ and the argument used in proposition 3 can be replicated. 
Proof of Lemma 1 The operating profit $\pi_{1}^{j}\left(x_{1}^{j}\right)$ given in (8) is clearly a decreasing function of $x_{1}^{j}$ for $x_{1}^{j} \in\left[x_{1}^{*}, x_{2}\right]$. Thus the quality will never exceed $x_{1}^{*}$.

For $x_{1}^{j} \in\left[\bar{x}_{1}, x_{1}^{*}\right]$, the operating profit $\pi_{1}^{j}\left(x_{1}^{j}\right)$ is increasing in $x_{1}^{j}$. Thus the quality will never be below $x_{1}^{*}$ and, consequently, the profit maximizing quality in $\left[\bar{x}_{1}, x_{2}\right]$ is $x_{1}^{*}$.

If the postal firm supplies the quality $x_{1}^{*}$ in market $j$, its operating profit $\pi_{1}^{j}\left(x_{1}^{*}\right)$ is positive if and only if $n^{j} \geq \bar{n}^{j} \equiv 6 k^{j} x_{2} /((2+\underline{\theta}) \underline{\theta})$.

Proof of Lemma 2 To prove the lemma, we show that it is impossible to have simultaneously $n \geq \bar{n}^{u}$ and $(1-n) \geq \bar{n}^{r}$. Summing these two conditions, we have $1 \geq \bar{n}^{u}+\bar{n}^{r}=6 k x_{2} /((2+\underline{\theta}) \underline{\theta})$, or equivalently $k \leq$ $\frac{(2+\underline{\theta}) \underline{\theta}}{6 x_{2}}$. But this condition is not compatible with the assumption of $k \geq \underline{k}=$ $\frac{1+2 \theta}{2 x_{2}}$. Hence, it is not possible to have the postal firm supplying the quality $x_{1}^{*}$ on the two markets. And, given that $\pi_{1}^{u}\left(x_{1}^{*}\right)>\pi_{1}^{r}\left(x_{1}^{*}\right)$, the rural markets will not be served by the postal firm.

Proof of Proposition 7. Given the specification of the welfare function in Equation 10, the welfare maximizing quality is equivalent to the quality level in the competitive case $\hat{x}_{1}^{o}$. We thus have three possible cases: First, the quality $\hat{x}_{1}^{o}$ is sustainable in the two scenarios, requiring $f \leq f_{2}, \check{f}_{2}$. Second, the quality $\hat{x}_{1}^{o}$ is sustainable in the standard case but not in the hybrid mail case. This will be the case if $\breve{f}_{2}<f \leq f_{2}$. This case is possible only if $\check{f}_{2}<f_{2}$ requiring $H<0$. Finally, the quality $\hat{x}_{1}^{o}$ is sustainable in the hybrid mail case but not in the standard competitive case. This will be the case if $f_{2}<f \leq \check{f}_{2}$. This case is possible only if $f_{2}<\check{f}_{2}$ requiring $H>0$. 


\section{Recent titles}

\section{CORE Discussion Papers}

2012/47 Pierre M. PICARD and Ridwan D. RUSLI. State owned firms: Private debt, cost revelation and welfare.

2012/48 Shin-Huei WANG, Luc BAUWENS and Cheng HSIAO. Forecasting long memory processes subject to structural breaks.

2012/49 Thierry BRECHET, Carmen CAMACHO and Vladimir M. VELIOV. Adaptive modelpredictive climate policies in a multi-country setting.

2012/50 Vladyslav NORA and Hiroshi UNO. Saddle functions and robust sets of equilibria.

2012/51 Thomas BAUDIN, David DE LA CROIX and Paula GOBBI. DINKs, DEWKs \& Co. Marriage, fertility and childlessness in the United States.

2012/52 David DE LA CROIX and Omar LICANDRO. The longevity of famous people from Hammurabi to Einstein.

2012/53 Marijn VERSCHELDE, Jean HINDRIKS, Glenn RAYP and Koen SCHOORS. School staff autonomy and educational performance: within school type evidence.

2012/54 Thierry BRECHET and Susana PERALTA. Markets for tradable emission permits with fiscal competition.

2012/55 Sudipto BHATTACHARYA, Claude D'ASPREMONT, Sergei GURIEV, Debapriya SEN and Yair TAUMAN. Cooperation in R\&D: patenting, licensing and contracting.

2012/56 Guillaume WUNSCH, Michel MOUCHART and Federica RUSSO. Functions and mechanisms in structural-modelling explanations.

2012/57 Simone MORICONI, Pierre M. PICARD and Skerdilajda ZANAJ. Commodity taxation and regulatory competition.

2012/58 Yurii NESTEROV and Arkadi NEMIROVSKI. Finding the stationary states of Markov chains by iterative methods.

2012/59 Tanguy ISAAC and Paolo PIACQUADIO. Equity and efficiency in an overlapping generation model.

2012/60 Luc BAUWENS, Giuseppe STORTI and Francesco VIOLANTE. Dynamic conditional correlation models for realized covariance matrices.

2012/61 Mikhail ESKAKOV and Alexey ISKAKOV. Equilibrium in secure strategies.

2012/62 Francis BLOCH and Axel GAUTIER. Strategic bypass deterrence.

2012/63 Olivier DURAND-LASSERVE, Axel PIERRU and Yves SMEERS. Sensitivity of policy simulation to benchmark scenarios in CGE models: illustration with carbon leakage.

2013/1 Pierre PESTIEAU and Maria RACIONERO. Harsh occupations, health status and social security.

2013/2 Thierry BRECHET and Henry TULKENS. Climate policies: a burden or a gain?

2013/3 Per J. AGRELL, Mehdi FARSI, Massimo FILIPPINI and Martin KOLLER. Unobserved heterogeneous effects in the cost efficiency analysis of electricity distribution systems.

2013/4 Adel HATAMI-MARBINI, Per J. AGRELL and Nazila AGHAYI. Imprecise data envelopment analysis for the two-stage process.

2013/5 Farhad HOSSEINZADEH LOTFI, Adel HATAMI-MARBINI, Per J. AGRELL, Kobra GHOLAMI and Zahra GHELEJ BEIGI. Centralized resource reduction and target setting under DEA control.

2013/6 Per J. AGRELL and Peter BOGETOFT. A three-stage supply chain investment model under asymmetric information.

2013/7 Per J. AGRELL and Pooria NIKNAZAR. Robustness, outliers and Mavericks in network regulation.

2013/8 Per J. AGRELL and Peter BOGETOFT. Benchmarking and regulation.

2013/9 Jacques H. DREZE. When Borch's Theorem does not apply: some key implications of market incompleteness, with policy relevance today.

2013/10 Jacques H. DREZE. Existence and multiplicity of temporary equilibria under nominal price rigidities. 


\section{Recent titles}

\section{CORE Discussion Papers - continued}

2013/11 Jean HINDRIKS, Susana PERALTA and Shlomo WEBER. Local taxation of global corporation: a simple solution.

2013/12 Pierre DEHEZ and Sophie POUKENS. The Shapley value as a guide to FRAND licensing agreements.

2013/13 Jacques H. DREZE and Alain DURRE. Fiscal integration and growth stimulation in Europe.

2013/14 Luc BAUWENS and Edoardo OTRANTO. Modeling the dependence of conditional correlations on volatility.

2013/15 Jens L. HOUGAARD, Juan D. MORENO-TERNERO and Lars P. OSTERDAL. Assigning agents to a line.

2013/16 Olivier DEVOLDER, François GLINEUR and Yu. NESTEROV. First-order methods with inexact oracle: the strongly convex case.

2013/17 Olivier DEVOLDER, François GLINEUR and Yu. NESTEROV. Intermediate gradient methods for smooth convex problems with inexact oracle.

2013/18 Diane PIERRET. The systemic risk of energy markets.

2013/19 Pascal MOSSAY and Pierre M. PICARD. Spatial segregation and urban structure.

2013/20 Philippe DE DONDER and Marie-Louise LEROUX. Behavioral biases and long term care insurance: a political economy approach.

2013/21 Dominik DORSCH, Hubertus Th. JONGEN, Jan.-J. RÜCKMANN and Vladimir SHIKHMAN. On implicit functions in nonsmooth analysis.

2013/22 Christian M. HAFNER and Oliver LINTON. An almost closed form estimator for the EGARCH model.

2013/23 Johanna M. GOERTZ and François MANIQUET. Large elections with multiple alternatives: a Condorcet Jury Theorem and inefficient equilibria.

2013/24 Axel GAUTIER and Jean-Christophe POUDOU. Reforming the postal universal service.

\section{Books}

G. DURANTON, Ph. MARTIN, Th. MAYER and F. MAYNERIS (2010), The economics of clusters Lessons from the French experience. Oxford University Press.

J. HINDRIKS and I. VAN DE CLOOT (2011), Notre pension en heritage. Itinera Institute.

M. FLEURBAEY and F. MANIQUET (2011), A theory of fairness and social welfare. Cambridge University Press.

V. GINSBURGH and S. WEBER (2011), How many languages make sense? The economics of linguistic diversity. Princeton University Press.

I. THOMAS, D. VANNESTE and X. QUERRIAU (2011), Atlas de Belgique - Tome 4 Habitat. Academia Press.

W. GAERTNER and E. SCHOKKAERT (2012), Empirical social choice. Cambridge University Press.

L. BAUWENS, Ch. HAFNER and S. LAURENT (2012), Handbook of volatility models and their applications. Wiley.

J-C. PRAGER and J. THISSE (2012), Economic geography and the unequal development of regions. Routledge.

M. FLEURBAEY and F. MANIQUET (2012), Equality of opportunity: the economics of responsibility. World Scientific.

J. HINDRIKS (2012), Gestion publique. De Boeck.

\section{CORE Lecture Series}

R. AMIR (2002), Supermodularity and complementarity in economics.

R. WEISMANTEL (2006), Lectures on mixed nonlinear programming.

A. SHAPIRO (2010), Stochastic programming: modeling and theory. 